\title{
FISCALIDAD Y PRECIOS EN CASTILLA EN EL SIGLO XVII: LOS PRECIOS DEL VINO EN MADRID, 1606-1700*
}

JOSÉ IGNACIO ANDRÉS UCENDO

Universidad del País Vasco ${ }^{\text {a }}$

\begin{abstract}
This article deals with the relations between taxation and prices levels in seventeenth century Castile through an analysis of the influence of royal and municipal taxes on the retail prices of cheap wine in Madrid between 1606 and 1700. First part describes the taxes levied on cheap wine by the Castilian Crown and the town council in Madrid. Both kinds of taxes provided the Royal and the City Treasuries with the most important part of their tax revenues. Second part analyzes how the Royal and the city authorities estimated the monetary value of the taxes and excises levied on this beverage. Lastly, third part shows that the burden of the royal and municipal taxes levied on a litre of cheap wine rose during the period. If in 1606-10 both types of taxes amounted to around 30 per cent of the retail prices of a litre of cheap wine, in the last third of the century this percentage had risen to 60-65 per cent.
\end{abstract}

Keywords: Taxation, Prices, Urban History

JEL Code: E62, H2, H3, H7, K34 y N90

* Received 2 March 2010. Accepted 26 November 2010. Este trabajo ha sido realizado gracias al Ministerio de Ciencia e Innovación, que ha financiado los Proyectos de Investigación "Fisco y mercado: fiscalidad, derechos de propiedad y cambio institucional en la España del siglo XVII", HAR 2008-05425 y "Niveles de vida y desigualdad. Aproximación social y regional en la España preindustrial”, HAR200804078/HIS. Deseo agradecer a Emiliano Fernández de Pinedo y a Santiago Piquero, así como a los evaluadores anónimos, por sus sugerencias, que me han ayudado a mejorar el trabajo.

a Departamento de Historia e Instituciones Económicas. Facultad de Letras. Vitoria-Gasteiz, Paseo de la Universidad, 5, 01006. E-mail: joseignacio.andres@ehu.es 


\section{RESUMEN}

El presente artículo analiza la relación entre la fiscalidad y los precios en la Castilla del siglo XVII a través de un estudio de la influencia de los impuestos reales y municipales sobre el precio del litro de vino ordinario en Madrid entre 1606 y 1700 . El primer apartado presenta los diversos tributos reales y municipales cobrados sobre el vino en Madrid, y demuestra que este producto fue el que más ingresos fiscales aportó tanto a la Hacienda Real como a la municipal. La segunda parte estudia el modo en que las autoridades estimaban el valor de los impuestos monetarios y en especie cobrados recaudados sobre este producto. El tercer apartado muestra que el peso de los impuestos municipales y reales cobrados sobre el litro de vino creció a lo largo del período. Si hacia 1606-10 estos impuestos representaban el 30 por cien del precio de venta del vino, en el último tercio del siglo este porcentaje creció hasta el del 60-65 por cien.

Palabras clave: Fiscalidad, Precios, Historia Urbana

\section{INTRODUCCIÓN}

La subida de la carga fiscal es considerada como uno de los factores de más relieve de la crisis del siglo XVII. Las costosas guerras del período provocaron la expansión de los gastos de los estados europeos y el paralelo crecimiento de la carga fiscal, lo que provocó una redistribución de recursos desde el sector privado de la economía al público. Esta transferencia despertó oposiciones que se tradujeron en las numerosas revueltas y motines antifiscales de la época y sus efectos se hicieron sentir en todos los sectores de la economía europea ${ }^{1}$.

Castilla no escapó al alza de la carga fiscal que acabamos de mencionar. Entre 1577 y 1666 los ingresos tributarios de la Corona crecieron desde 2,6 millones de ducados en 1577 a 5,7 millones en 1666, cifra alrededor de la cual se estabilizaron hasta las medidas de rebaja de la carga tributaria de inicios de los $80^{2}$. Como en otros estados europeos, esta subida estuvo impulsada por el desarrollo de la fiscalidad indirecta y, en concreto, por un reducido grupo de impuestos, entre los que destacaron figuras ya tradicionales como la alcabala (cobrada desde mediados del siglo XIV) y otras nuevas, como los servicios de millones y los cientos, en vigor desde fines del siglo XVI y 1639, respectivamente. Si en 1577 la alcabala suministró a la

\footnotetext{
1 Bonney, (1999) y Stensgaard, (1978, pp. 38-ss).

2 Andrés y Lanza (2008, p. 176).
} 
Corona la mitad de sus ingresos fiscales, en 1666 esta figura, junto con los servicios de millones y los cuatro cientos, proporcionó nada menos que el 72 por cien de los mismos.

La alcabala, cientos y millones tenían en común que gravaban las compraventas de una amplia gama de productos entre los que destacaron las carnes y, en especial, el vino.

Suele admitirse que la proliferación de impuestos indirectos a lo largo del siglo XVII tuvo repercusiones negativas sobre la economía castellana. Ya desde fines del siglo XVI existía una clara conciencia de los perjudiciales efectos de esta tributación, según se desprende del testimonio en las Cortes de 1595 de Jerónimo de Salamanca, donde se señalaba que las sisas sobre productos de consumo masivo como el vino provocaban la subida de los precios de esta bebida ${ }^{3}$. A lo largo del siglo XVII este razonamiento gozó de una gran popularidad y se extendió la convicción de que el alza de precios causada por los tributos indirectos (y en particular por aquellos cobrados sobre el vino, carnes y aceite para recaudar los millones) contribuía a la subida de los costes de producción de las manufacturas castellanas y reducía los niveles de demanda ${ }^{4}$.

Esta visión ha sido asumida por la investigación y su influencia es visible en los trabajos de historia económica y social de Castilla y España. En un artículo clásico de 1978 F. Ruiz Martín (1978, pp. 37-47) atribuyó a la fiscalidad indirecta un papel esencial en la decadencia de las ciudades castellanas a lo largo del siglo XVII y recientemente A. Marcos Martín (2006, p. 186) ha señalado cómo el desarrollo de este tipo de tributación afectó al comercio y manufactura: “... no sólo por el lado de la oferta (debido al ... tirón al alza de los diferentes costes y en primer término de los salarios), sino también por el de la demanda (a causa de la caída del consumo de bienes y artículos no imprescindibles para la subsistencia)."

Pareceres como el de A. Marcos Martín recogen la opinión ya formulada en el siglo XVII acerca de las relaciones entre la fiscalidad y los niveles de precios y salarios en la Castilla de la época, pero, como señala el mismo autor, esta visión no ha sido verificada, por lo que el propósito de las siguientes páginas es ofrecer un elemento que ayude a medir las relaciones entre precios y tributos en la Castilla del XVII a través de un estudio del peso de los impuestos sobre el vino ordinario en Madrid entre 1606 y 1700.

El vino era uno de los productos más importantes en la dieta de los castellanos del Seiscientos y soportó una amplia gama de impuestos, lo que hizo a A. Huetz de Lemps (1967, vol II, pp. 850-51) señalar que esta bebida fue el producto más gravado por todo tipo de tributos en la Castilla del Seiscientos. El relieve de los tributos reales sobre el vino no ha pasado

3 Andrés, (1999, pp. 118-119) y Marcos Martín, (2006, pp. 190-191). Vid. también Fortea, (1981).

${ }^{4}$ García Sanz, (1991, p. 15). BN, Mss, 9.400 y AHN, Consejos, legajo, 7.175-27. 
desapercibido a la historiografía, que en las últimas décadas también ha llamado la atención sobre los impuestos municipales sobre esta bebida ${ }^{5}$.

El apartado 1 presenta los diversos impuestos, municipales y reales, cobrados sobre el vino ordinario en el Madrid del siglo XVII y muestra que fue el producto que más ingresos fiscales aportó a la Hacienda Real y a la de la villa, aunque a causa de las estrechas conexiones entre ambos fiscos la distinción entre tributos reales y municipales resultó más bien teórica y buena parte de los impuestos municipales que gravaron el consumo de esta bebida en la capital financiaron en realidad las necesidades de la Corona.

Los tributos sobre el vino recaudados en Madrid combinaban recargos monetarios y en especie. El apartado 2 explica el método usado por los contadores madrileños para estimar el valor de los tributos cobrados por cada arroba de vino, que conocemos gracias a un memorial de 1667. Esto nos ha permitido calcular qué porcentaje del precio del litro de vino ordinario en Madrid correspondía a los diversos tributos municipales y reales, aspecto que constituye el principal objetivo de este trabajo y al que se dedica la tercera y última parte del mismo.

En 1989 A. Gutiérrez Alonso (1989, p. 160) indicó que en 1657-61 los tributos representaban el 50 por cien del precio de venta del vino en Valladolid y según se muestra en el apartado 3 este porcentaje alcanzó el 60-65 por cien del precio del litro de vino ordinario en Madrid a fines de siglo, siendo reseñable que los impuestos reales y los impuestos municipales introducidos para financiar las necesidades de la Corona representaban alrededor del 50 por cien de su precio, lo que ilustra la trascendencia de las conexiones entre la fiscalidad real y municipal. Sin duda, el elevado peso de la carga fiscal sobre el vino constituye una de las principales peculiaridades del caso madrileño y castellano. Como hemos señalado, el desarrollo de la tributación indirecta en la Castilla del siglo XVII se incluye dentro de una tendencia más general, visible en otras áreas como Holanda o Inglaterra (después de 1688), pero la singularidad del caso madrileño (y castellano) reside en que una parte sustancial de la carga fiscal recayó sobre el vino, algo que se explica por el carácter más bien inelástico de la demanda de esta bebida ${ }^{6}$.

\section{EL VINO COMO FUENTE DE INGRESOS FISCALES}

Al igual que el resto del Reino, Madrid no escapó al alza de la carga fiscal durante el siglo XVII provocado por la necesidad de atender las crecientes exigencias de la Monarquía, a la que se añadió la paralela subida de la carga fiscal municipal, fruto de las estrechas relaciones entre la hacienda de la villa

\footnotetext{
5 Yun, (1990, pp. 35-ss); García García, (1996, pp. 68-78) y Andrés, (2006, pp. 45-46).

6 't Hart (1999) y O’Brien y Hunt, (1999).
} 
y el fisco real ${ }^{7}$. Entre 1629 y 1679 Madrid otorgó donativos a la Real Hacienda por un valor de 19 millones de ducados. La mayor parte de los mismos se concedieron entre 1653 y 1678 , cuando la capital sirvió a la Monarquía con 17 millones de ducados en varias operaciones ${ }^{8}$. Para reunir las sumas ofrecidas a la Corona en cada donativo, Madrid recurrió al crédito municipal, emitiendo los efectos de villa, en la práctica censos consignativos con un interés que descendió del 10 por cien original al 5 por cien desde 1680. Para pagar los intereses de los efectos la Corona autorizó a su capital a crear nuevos tributos municipales, y además desde 1653 comenzó a transferir a Madrid la mayor parte de los servicios de millones recaudados en la provincia. Esto último significó el nacimiento de las Sisas Reales, término usado por los contadores madrileños para designar los servicios de millones cedidos a la capital por la Corona a cambio de donativos. Las Sisas Reales se incluyeron dentro de los ingresos municipales, junto los demás tributos recaudados por Madrid, y a finales del siglo la villa controlaba más del 80 por cien de los servicios de millones recaudados en la ciudad y su distrito fiscal ${ }^{9}$.

Como resultado, el valor de las pagas de los tributos reales (alcabala, servicios de millones y cuatro cientos) y de los tributos municipales (tributos municipales más las Sisas Reales) cobrados en Madrid creció, según nuestras estimaciones, desde poco más de 220 millones de mrs en 1621 hasta 861 millones en 1679. Aunque a comienzos de los 80 las pagas de estos tributos iniciaron su caída, a fines del siglo su monto oscilaba alrededor de los 550 millones de mrs anuales, cifra todavía muy superior a la de $1621^{10}$.

La subida de la carga tributaria, tanto real como municipal, se afrontó en Madrid a través de tributos sobre productos de consumo muy difundido entre la población, entre los que destacaron las carnes y, en especial, el vino. Como resultado, los tributos que gravaban cada litro de vino de vino ordinario crecieron desde 3,6 mrs/litro en 1606 hasta 24,8 mrs en 1667 (apéndice). En paralelo, el valor anual de las recaudaciones de los tributos municipales y reales sobre este producto aumentó de forma visible. Varios indicios permiten asegurar que en 1606-1610 el valor medio anual de todos los tributos sobre el vino en Madrid osciló alrededor de los 30-35 millones de mrs, cantidad que creció hasta los 276,5 millones de mrs en 1681-85. Aunque a partir de 1686 el valor de las pagas de los tributos sobre el vino cayó, el

\footnotetext{
7 De la Hoz (1988) y Andrés (2006) y (2007).

8 Andrés (2007, pp. 71-72).

9 Aunque en sentido estricto las sisas fueran un medio de recaudar impuestos indirectos, en la documentación municipal este término era sinónimo de los impuestos sobre el consumo, monetarios o en especie. De la Hoz, (1988, p. 383).

10 Andrés, (2006, pp. 69-70). Las alcabalas, millones e impuestos municipales representaban el grueso de los tributos pagados por los madrileños a la Real Hacienda en el siglo XVII. Sin embargo, la carga fiscal que recayó sobre los habitantes de la villa debió de ser mayor puesto que en nuestras estimaciones no se incluye el valor del estanco del tabaco, introducido en 1634. Aunque no hemos podido recopilar el valor de esta renta, sabemos que no era desdeñable. Hacia 1670 y 1680 el tabaco estaba arrendado en unos 70 millones de mrs anuales.
} 
descenso fue moderado y entre 1686 y 1700 se estabilizó alrededor de los 230 millones de mrs anuales, cifra que representaba entre el 41-43 por cien del valor anual de las recaudaciones de todos los tributos municipales y reales, lo que atestigua el peso del vino como fuente de ingresos fiscales para la Hacienda Real y la de la villa.

Si comenzamos nuestro análisis acerca de los tributos sobre el vino en el Madrid del siglo XVII con los impuestos reales, el vino pagó la alcabala, los cuatro cientos y los servicios de millones. Para recaudar la alcabala y los cuatro unos por ciento se recurrió a gravámenes monetarios, cuyo valor fue pequeño en comparación con el de los tributos aplicados para recaudar los millones y los tributos municipales, como se desprende del informe de 1667, donde se afirmaba que cada arroba de vino estaba gravada por $40 \mathrm{mrs}$ en concepto de alcabalas y cientos, el 10 por cien del valor de todos los gravámenes (monetarios y en especie) sobre este producto en la misma fecha ${ }^{11}$.

Mayor relieve tuvieron las cargas impuestas para cobrar los millones. Desde 1601 la arroba de vino introducida en Madrid pagaba la sisa de la Octava Parte, equivalente a 1,125 azumbres de la medida menor, y a ella se añadieron más tributos monetarios y en especie a lo largo del siglo. Los servicios de millones fueron reemplazados en 1631 por el Medio de la Sal, aunque tras el fracaso de éste se reintrodujeron a mediados de 1632. En dicho año comenzó a correr el servicio de los 24 millones y a fin de pagarlo se recuperó la sisa de la Octava Parte, y además se introdujo un recargo monetario que desde 1636 ascendió a 27 mrs por arroba. A estos gravámenes se sumaron otros 4,5 mrs por arroba de vino para el servicio de los 8.000 soldados en 1638, cuando también apareció el servicio de las Quiebras. Una de las peculiaridades de este servicio reside en que se otorgó a las ciudades y villas de Castilla la facultad de escoger los medios de pago de las Quiebras y Madrid optó por combinar cargas monetarias y en especie, imponiendo otros $18 \mathrm{mrs}$ por arroba más una sisa de 1,125 azumbres de la medida menor por arroba (sisa del Vino de Quiebras o del Consejo) desde abril de 1639. Por último, en verano de 1657 se creó el servicio de los Tres Millones y se impusieron otros 44 mrs por arroba de vino ${ }^{12}$.

Según hemos indicado, la mayoría de los servicios de millones cobrados en la villa y su distrito fiscal fueron transferidos por la Monarquía al municipio a cambio de cuantiosos donativos. El proceso comenzó en 1653, cuando Madrid recibió el servicio de los 8.000 soldados a cambio de un donativo de 220.000 ducados $^{13}$. En 1657 la Monarquía cedió a la capital los Tres Millones y, por último, en 1665 y en 1678 la villa recibió el control del vino de las Quiebras de Millones y de los gravámenes monetarios para el pago de los 24 millones respectivamente. Como resultado, después de 1678 la

11 AVM, Secretaría, 2-243-7.

12 De la Hoz (1988, pp. 372-ss) y AVM, Secretaría, 2-243-7.

13 AVM, Secretaría, 3-297-31. 
Corona sólo conservaba la cobranza de la sisa de la Octava parte, mientras que el resto de las cargas aplicadas sobre el vino para cobrar los millones habían pasado a formar parte de los ingresos municipales ${ }^{14}$.

Además de la alcabala, cientos y millones, el vino también soportó tributos monetarios y en especie para recaudar los crecientes tributos municipales introducidos en los dos primeros tercios del XVII, que se añadieron a los 16 mrs por arroba aplicados desde 1581 por la llamada Sisa Ordinaria.

En 1611 el municipio introdujo las sisas de la Sexta Parte, término que designaba un variado conjunto de gravámenes entre los que destacaban 16 mrs por arroba de vino. Otros $16 \mathrm{mrs}$ por se aplicaron en 1618 para pagar la sisa de la Plaza. En 1630 se añadieron 8 mrs por arroba para recaudar la sisa del Vino de la Cárcel, y en junio de 1637 se aplicaron otros 18,3 mrs por arroba para cobrar la sisa del Vino de la Salud, cuyo fin era aportar ingresos para evitar el contagio de la epidemia de peste de Málaga. La entrada de impuestos monetarios de origen municipal sobre el vino terminó en 1644 y 1657, cuando la villa introdujo la sisa del Vino de Lérida (16 mrs por arroba de vino) y la del Vino de Olivenza $\left(22,2 \mathrm{mrs}\right.$ por arroba) respectivamente ${ }^{15}$.

La sucesión de gravámenes que acabamos de indicar sugiere que en la primera mitad del siglo XVII el municipio había optado por el recurso a tributos en moneda sobre el vino. Es muy posible que a comienzos de los 60 estos gravámenes parecieran excesivos a las autoridades de la villa, y esto explicaría el recurso a cargas en especie para el cobro de los últimos tributos municipales sobre el vino. En 1663 Madrid introdujo la sisa de la Bajada de Medidas y por último en 1667 apareció la sisa del Error de Medidas. Cada una de estas dos sisas equivalía a 3,5 cuartillos (0,875 azumbres de la medida menor).

Aunque pudiera sostenerse que el propósito de los numerosos tributos municipales sobre el vino que acabamos de citar era proporcionar a la villa los ingresos necesarios para el pago de sus necesidades ordinarias, en realidad no fue así y varios de los tributos municipales arriba indicados proporcionaron a Madrid ingresos para pagar sus intereses a los efectistas que prestaban a la capital los fondos ofrecidos a la Monarquía en los donativos a que aludimos al inicio.

De las sisas municipales que gravaban el vino en Madrid, sólo la sisa Ordinaria, la de la Sexta Parte, la de la Plaza y la del Vino de la Cárcel financiaron necesidades que pudiéramos definir como municipales en sentido estricto, y a ellas habría que añadir, aunque con reservas, la sisa del vino de la Salud. La sisa Ordinaria se creó en 1581 para reunir fondos con los que combatir la amenaza de una epidemia de peste y sus pagas luego sirvieron para costear los gastos de limpieza y empedrado. La sisa del vino de la Sexta Parte financió los gastos causados por el retorno de la Corte y sus pagas luego

14 De la Hoz, (1988, pp. 380-ss) y Andrés, (2006, pp. 47-49).

15 De la Hoz, (1988, pp. 377-ss). AVM, Secretaría 3-303-21 y 3-276-10. 
se destinaron a mantener los hospitales de la capital. Por último, las sisas del vino de la Plaza y del vino de la Cárcel sirvieron para sufragar las obras de la Plaza Mayor y de la cárcel de la villa, respectivamente ${ }^{16}$. El carácter de la llamada sisa del Vino de la Salud fue más ambiguo. Introducida en 1637 para financiar la lucha contra la epidemia de peste que afectó a Málaga en dicho año, entre 1638 y 1651 el municipio decidió usarla para ayudar a pagar las Quiebras de Millones, lo que constituye una significativa prueba de lo borroso de los límites entre los impuestos reales y municipales en el Madrid del XVII ${ }^{17}$.

Los tributos creados por el municipio sobre el vino para pagar los intereses de los efectos de villa fueron la sisa del Vino de Lérida, la del Vino de Olivenza y las sisas de la Bajada y Error de Medidas. La sisa del Vino de Lérida apareció en 1644 a cambio de un donativo de 100.000 ducados para el asedio de Lérida y en la primavera de 1657 se impuso la sisa del vino de Olivenza, previa concesión de otro donativo de 200.000 ducados para los gastos del cerco de esta ciudad. La sisa del vino de la Bajada de Medidas se introdujo en 1663 tras un donativo de 500.000 escudos, y por último en 1667 apareció la sisa del vino del Error de Medidas después otro donativo de 500.000 ducados $^{18}$.

Como resultado de la introducción de impuestos municipales sobre el vino destinados a atender el pago de los intereses a los efectistas, desde 1644 se desarrolló una tendencia en virtud de la cual a fines del siglo XVII la mayor parte de los ingresos obtenidos por la hacienda de la villa de sus tributos sobre el vino servía en realidad para financiar las necesidades de la Corona.

El Cuadro 1 indica que entre 1607 y 1640 las pagas de los impuestos municipales sobre el vino se destinaron en su totalidad a pagar los gastos de la villa. Sin embargo, tras la introducción en 1644 de la sisa del vino de Olivenza una parte creciente de las recaudaciones de estos tributos se destinó a pagar los intereses de los efectos $\mathrm{y}$, por tanto, a financiar las necesidades de la Corona de modo indirecto. En 1661-65 el 44 por cien del valor anual de las pagas de los tributos municipales sobre el vino se dedicaba a tal fin y en el último tercio del siglo este porcentaje se estabilizó alrededor del 65 por cien, debiendo subrayar que esta suma debió de ser todavía mayor, puesto que en varios momentos de las años 70 y 80 los ingresos de la sisa del vino Ordinaria de la Sexta Parte, de la Plaza y de la Cárcel se usaron para pagar los intereses a los efectistas ${ }^{19}$.

Si al valor de los tributos municipales sobre el vino del Cuadro 1 añadimos el de los servicios de millones transferidos a la villa previa concesión de donativos a la Corona, (Sisas Reales) y el de los tributos sobre el vino

\footnotetext{
16 De la Hoz, (1988, p. 378).

17 AVM, Secretaría, 2-243-7 y AHN, Consejos, Alcaldes, libro 1.279, fol.9.

18 De la Hoz, (1988, p. 380).

19 AVM, Secretaría, 4-333-16 y 2-350-17, 3-268-16 y 4-333-16.
} 


\section{CUADRO 1}

RECAUDACIONES DE LOS IMPUESTOS MUNICIPALES SOBRE EL VINO DESTINADOS A FINANCIAR LOS GASTOS DEL CONCEJO Y LAS NECESIDADES DE LA CORONA, MADRID 1607-1700

(En millones de mrs corrientes y en porcentajes)

\begin{tabular}{|l|c|c|c|c|c|}
\hline & \multicolumn{2}{|c|}{ Necesidades concejo } & \multicolumn{2}{c|}{ Necesidades Corona } & Total \\
\hline & Valor & $\%$ & Valor & $\%$ & \\
\hline $1607-1610$ & 14,5 & 100,0 & & & $\mathbf{1 4 , 5}$ \\
\hline $1611-1615$ & 34,0 & 100,0 & & & $\mathbf{3 4 , 0}$ \\
\hline $1616-1620$ & 54,0 & 100,0 & & & $\mathbf{5 4 , 0}$ \\
\hline $1621-1625$ & 76,0 & 100,0 & & & $\mathbf{7 6 , 0}$ \\
\hline $1626-1630$ & 80,0 & 100,0 & & & $\mathbf{8 0 , 0}$ \\
\hline $1631-1635$ & 85,0 & 100,0 & & & $\mathbf{8 5 , 0}$ \\
\hline $1636-1640$ & 66,0 & 100,0 & & & $\mathbf{6 6 , 0}$ \\
\hline $1641-1645$ & 48,0 & 93,0 & 3,6 & 7,0 & $\mathbf{5 1 , 6}$ \\
\hline $1646-1650$ & 42,0 & 77,5 & 12,2 & 22,5 & $\mathbf{5 4 , 2}$ \\
\hline $1651-1655$ & 53,2 & 82,0 & 11,6 & 18,0 & $\mathbf{6 4 , 8}$ \\
\hline $1656-1660$ & 57,4 & 70,5 & 24,0 & 29,5 & $\mathbf{8 1 , 4}$ \\
\hline $1661-1665$ & 55,6 & 56,0 & 43,6 & 44,0 & $\mathbf{9 9 , 4}$ \\
\hline $1666-1670$ & 53,5 & 40,0 & 79,6 & 60,0 & $\mathbf{1 3 3 , 0}$ \\
\hline $1671-1675$ & 52,2 & 36,0 & 92,4 & 64,0 & $\mathbf{1 4 4 , 6}$ \\
\hline $1676-1680$ & 54,7 & 36,0 & 96,8 & 64,0 & $\mathbf{1 5 1 , 5}$ \\
\hline $1681-1685$ & 41,5 & 34,0 & 80,2 & 66,0 & $\mathbf{1 2 1 , 7}$ \\
\hline $1686-1690$ & 35,7 & 35,0 & 65,0 & 65,0 & $\mathbf{1 0 0 , 7}$ \\
\hline $1691-1695$ & 36,2 & 34,0 & 65,6 & 63,0 & $\mathbf{1 0 6 , 0}$ \\
\hline $1696-1700$ & 35,0 & 36,0 & 63,1 & 64,0 & $\mathbf{9 8 , 0}$ \\
\hline
\end{tabular}

Fuentes: Andrés. (2006) y apéndice. Impuestos para financiar las necesidades del concejo (sisa del Vino Ordinaria; sisa del Vino de la Sexta Parte; sisa del Vino de la Plaza; Sisa del Vino de la Cárcel y sisa del Vino de la Salud en 1637 y entre 1651-1700). Impuestos para financiar las necesidades de la Corona (sisa del Vino de Lérida; sisa del Vino de Olivenza y sisas de la la Bajada y del Error de Medidas).

destinados al pago de los impuestos reales (alcabalas, millones y cientos) obtenemos una imagen todavía más precisa del auténtico peso de las exigencias de la Monarquía en el alza del valor de las recaudaciones de todos los tributos sobre esta bebida en el Madrid del XVII. El Cuadro 2 ofrece el valor medio anual de todos los impuestos sobre el vino en Madrid entre 1681 y 1700 , 


\section{CUADRO 2}

VALOR MEDIO ANUAL DE LOS IMPUESTOS SOBRE EL VINO EN MADRID CREADOS PARA FINANCIAR LAS NECESIDADES REALES Y MUNICIPALES

(En millones de mrs corrientes y en porcentajes)

\begin{tabular}{|l|c|c|c|c|c|}
\hline & $\mathbf{( 1 )}$ & $\%$ & $\mathbf{( 2 )}$ & $\%$ & TOTAL \\
\hline $1681-85$ & 235,0 & 85,0 & 41,5 & 15,0 & $\mathbf{2 7 6 , 5}$ \\
\hline $1686-90$ & 202,0 & 85,0 & 35,7 & 15,0 & $\mathbf{2 3 8 , 0}$ \\
\hline $1691-95$ & 201,0 & 85,0 & 36,2 & 15,0 & $\mathbf{2 3 7 , 5}$ \\
\hline $1696-00$ & 194,0 & 85,0 & 35,0 & 15,0 & $\mathbf{2 2 9 , 0}$ \\
\hline
\end{tabular}

(1): impuestos creados para financiar las necesidades reales. (2): impuestos municipales creados para financiar las necesidades municipales. TOTAL: (1)+(2). Fuentes: Andrés, (2006), apéndice 1.

divididos en dos grupos: el de aquellos impuestos destinados a atender las necesidades ordinarias del municipio y el de los creados para financiar las necesidades de la Corona. Dentro de este último grupo hemos incluido los gravámenes y sisas aplicados para el cobro de la alcabala, los cientos y los servicios de millones más las Sisas Reales y los tributos municipales introducidos a cambio de la concesión de donativos a la Corona del Cuadro 1.

El Cuadro 2 demuestra que entre 1681 y 1700 el 85 por cien de las pagas de los tributos sobre el vino en Madrid procedía de figuras que financiaban las necesidades de la Corona. Si consideramos que en 1606-10 el valor medio anual de todos los tributos reales y municipales sobre el vino osciló alrededor de 30-35 millones de mrs, puede concluirse diciendo que las necesidades de la Monarquía fueron las responsables del notable crecimiento del valor anual de las recaudaciones de los tributos sobre el vino en el Madrid del siglo XVII y que esto se hizo de forma directa, a través de los gravámenes y sisas aplicados para el cobro de la alcabala y los cientos más los servicios de millones, e indirecta, a través de la mediación del municipio, varios de cuyos impuestos se habían introducido a cambio de la concesión de donativos.

\section{LAS NORMAS SEGUIDAS EN EL MADRID DEL XVII PARA ESTIMAR EL VALOR DE LOS TRIBUTOS SOBRE EL VINO}

Gracias al memorial de 1667 citado al inicio conocemos las normas seguidas por los contadores madrileños para estimar el valor de los tributos municipales y reales sobre cada arroba de vino. Estas normas se mantuvieron, con breves interrupciones, hasta inicios de 1683, cuando el municipio unificó todos los tributos municipales (incluyendo las Sisas Reales) en moneda y en especie sobre el vino en un gravamen de 9,5 reales por arroba, 
CUADRO 3

EVOLUCIÓN DEL NÚMERO DE AZUMBRES OBTENIDAS DE CADA ARROBA DE VINO EN MADRID EN EL SIGLO XVII

\begin{tabular}{|l|c|c|c|c|}
\hline Fecha & M. Mayor & Litros & M. Menor & Litros \\
\hline $1600-01$ & 8,0 & 2,016 & & \\
\hline $1601-31$ & 8,0 & 2,016 & 9,12 & 1,76 \\
\hline $1631-32$ & 8,0 & 2,016 & 8,0 & 2,0 \\
\hline $1632-38$ & 8,0 & 2,016 & 9,12 & 1,76 \\
\hline 1639 & 8,0 & 2,016 & 10,42 & 1,54 \\
\hline 1640 & 8,0 & 2,016 & 13,0 & 1,23 \\
\hline 1641 & 8,0 & 2,016 & 10,8 & 1,49 \\
\hline $1642-3$ & 8,0 & 2,016 & 10,25 & 1,58 \\
\hline 1644 & 8,0 & 2,016 & 10,68 & 1,51 \\
\hline $1645-62$ & 8,0 & 2,016 & 11,12 & 1,45 \\
\hline 1663 & 8,0 & 2,016 & 11,6 & 1,39 \\
\hline $1664-700$ & 8,0 & 2,016 & 12,0 & 1,34 \\
\hline
\end{tabular}

M. Mayor: número de azumbres de la medida mayor por arroba M. Menor: número de azumbres de la medida menor por arroba. Fuente: AVM, Secretaría, 3-276-10.

quedando excluidos del mismo la sisa de la Octava Parte de los servicios de Millones, todavía cobrada por la Real Hacienda, más los gravámenes creados para contribuir al pago de la alcabala y los cientos, arrendados por los gremios de la villa.

El memorial de 1667 también indica las cantidades que los taberneros madrileños y cosecheros de los pueblos de los alrededores debían abonar cuando introducían una arroba de vino en Madrid. A tal fin, las autoridades de la villa colocaban en las puertas de la capital unos aranceles donde se indicaban las sumas que estos grupos debían pagar a los arrendadores de los impuestos por cada arroba de vino que introducían en la ciudad. Estos aranceles también se empleaban para conocer las sumas que los arrendadores debían percibir de los herederos de viñas locales cuando se realizaba el aforo del vino encerrado en sus bodegas ${ }^{20}$.

El cálculo del valor de los tributos monetarios sobre cada litro de vino no ofrece excesivas dificultades, ya que basta con dividir el valor total de los recargos monetarios impuestos por cada arroba de vino por el número de litros de la misma $(16,1)$.

${ }^{20}$ AVM, Secretaría, 3-276-10. 
Más complicado resulta estimar el valor monetario de los tributos en especie cobrados sobre el vino, aspecto de especial relieve dada la importancia de este género de impuestos en el Madrid del siglo XVII. La arroba de vino llegó a estar gravada por cuatro impuestos en especie en la capital: la sisa de la Octava Parte, la sisa del vino de las Quiebras, y las sisas de la Bajada y del Error de Medidas. Cuando se introducía un nuevo tributo en especie, la cantidad de vino recibida por el consumidor al comprar una azumbre de esta bebida disminuía sin que variara el precio. El valor monetario del impuesto consistía en el valor del volumen de vino que el consumidor había pagado y que sin embargo no había recibido. El informe de 1667 indica cómo calculaban los contadores municipales el valor monetario de los tributos en especie cobrados en Madrid sobre cada arroba de vino, lo que nos permite estimar el valor de estos tributos por cada litro de vino ordinario.

La arroba de vino se había dividido tradicionalmente en 8 azumbres, cada una de las cuales constaba a su vez de 4 cuartillos $^{21}$. Las condiciones del primer servicio de los 18 millones de 1601 ordenaban que la sisa de la Octava Parte se cobrara en la última venta del vino, de modo que los consumidores recibieran una octava parte menos de esta bebida por cada azumbre adquirida sin que variara su precio, actuando los vendedores de intermediarios entre los compradores y las autoridades. Esto provocó cambios en la medida con que se vendía el vino al por menor en las ciudades y villas del reino: la azumbre Hasta 1601 la azumbre había tenido algo más de 2 litros de vino, pero desde esa fecha su volumen se redujo en una octava parte, (un 12,5 por cien), cayendo de 2,01 litros hasta 1,76 y así nació la azumbre de vino de la medida menor, usada por los taberneros en sus ventas de vino a los consumidores (Cuadro 3).

Como desde 1601 el volumen de la azumbre de vino se había reducido a 1,76 litros sin que variara el volumen de la arroba, el número de azumbres obtenidas de cada arroba aumentó de 8 a 9,125; de ahí que en los textos de la época se afirmara que desde 1601 el número de azumbres había crecido de 8 a 9,125. Si exceptuamos un breve período entre noviembre de 1631 y el verano de 1632, en que los servicios de millones se suprimieron a causa del Medio de la Sal y la arroba volvió a tener 8 azumbres, esta cantidad se mantuvo hasta abril de 1639. En ese año comenzó una fase que duró hasta 1663 en la que el número de azumbres de la medida menor de cada arroba de vino creció hasta 12 a causa de la introducción de varios tributos en especie.

La introducción de la sisa del Vino de Quiebras de Millones en abril de 1639, equivalente a otras 1,125 azumbres, produjo un nuevo crecimiento del número de azumbres de la medida menor, que subió de 9,125 a 10,25. En noviembre del mismo año se produjo otro cambio. En octubre de 1639 las Cortes habían decidido reducir todos los tributos monetarios y en especie sobre el vino para recaudar los servicios de millones a un tributo en especie, ordenando que en todo el Reino se obtuvieran 11,5 azumbres por arroba.

${ }^{21}$ Hamilton, (1975, p. 183) y AVM, Secretaría, 2-243-7. 
Como la capital había creado en abril del mismo año una sisa de 1,125 azumbres para cobrar las quiebras, el municipio decidió obtener 13 azumbres de la medida menor de cada arroba. Esta cantidad se mantuvo hasta abril de 1641, cuando la reforma de octubre de 1639 se retiró y el número de azumbres de la medida menor obtenido de cada arroba regresó a las 10,25 de abril de $1639^{22}$.

Los dos últimos tributos en especie fueron introducidos por el municipio en la década de los 60. En julio de 1663 Madrid creó la sisa de la Bajada de Medidas, equivalente a 3,5 cuartillos, con lo que el número de azumbres de la medida menor obtenido de cada arroba de vino aumentó de 11,125 hasta 12, cifra que se mantuvo a lo largo del resto del siglo y durante el siglo XVIII.

Tras el fracaso de la reforma de 1639-41 el número de azumbres de la medida menor había descendido de 13 a 10,25. Como entre abril de 1641 y julio de 1663 no se había creado ningún impuesto en especie sobre el vino, puede resultar sorprendente descubrir que en la última fecha el número de azumbres de la medida menor de cada arroba de vino en Madrid fuera 11,125 y no las 10,25 teóricas. Esto se explica porque entre 1644 y 1663 los taberneros de la capital cobraron a los consumidores de forma ilegal un tributo en especie de otros 3,5 cuartillos, en virtud del cual el número auténtico de azumbres de la medida menor obtenido por cada arroba de vino en la villa creció de las teóricas 10,25 a 11,125. En concreto, el 4 de junio de 1644 el municipio había impuesto la sisa del Vino de Lérida, equivalente a $16 \mathrm{mrs}$ por arroba. El almotacén de la capital aprovechó esta ocasión para crecer sin autorización ni del municipio ni de la Corona el número de azumbres de la medida menor en 3,5 cuartillos, desde las 10,25 en vigor desde inicios de 1641 hasta 11,125. De esta manera, la sisa de Lérida se duplicaba con un gravamen en especie ilegal, cuya cobranza se superponía a la de los $16 \mathrm{mrs}$ por arroba de vino, y el volumen de la azumbre de la medida menor se redujo casi un 8 por cien, desde 1,58 litros a 1,45. Resulta poco probable que la Corona desconociera este fraude y en agosto de 1667 la Reina Regente decidió consentir la cobranza de esta sisa recaudada por los taberneros ilegalmente desde 1644 a cambio de un donativo de 500.000 ducados, lo que marcó el nacimiento de la sisa del Error de Medidas ${ }^{23}$.

Como resultado de la trayectoria que acabamos de describir, a lo largo del Seiscientos el volumen de vino que recibía el consumidor madrileño al comprar una azumbre de la medida menor de esta bebida en cualquier taberna de la villa descendió un 24 por cien, desde los 1,76 litros de 1606 a 1,34 de 1700 .

Dado que el número de azumbres de la medida menor creció de 8 a 12 a lo largo del siglo y que la sisa de la Octava Parte siempre fue 1,125 azumbres de la medida menor, el tipo impositivo representado por esta sisa en el Madrid del XVII fue en realidad inferior al teórico 12,5\% fijado en las condiciones de

22 AHN, Consejos, libro 1.224, fol. 250 y 1226, fol. 84 .

23 AVM, Secretaría, 2-243-7. 
los servicios de millones. Como resultado de la creación de nuevos impuestos en especie y del aumento del número de azumbres de la medida menor obtenidas de cada arroba, este tipo debiera haberse reducido del 12,5 por cien en 1606 hasta el 9,375 por cien desde 1663. Sin embargo, los porcentajes cobrados por la sisa de la Octava Parte en la capital fueron incluso menores. En 1606 esta sisa representaba el 11 por cien de la postura del vino en vez del 12,5 y en el último del siglo su valor osciló alrededor del 8,3 por cien en vez del teórico 9,375. La causa de esta diferencia radica en la existencia de impuestos que no octavaban, lo que rebajaba el valor de la sisa de la Octava Parte.

Los impuestos que no octavaban eran las Sisas Municipales cobradas en moneda, que en 1667 ascendían a $112 \mathrm{mrs}$ por arroba $(9,3 \mathrm{mrs}$ por azumbre de la medida menor) más los 44,3 mrs por arroba de la sisa del vino de los Tres Millones. Así, en 1668, fecha en que la postura de la azumbre de vino de la medida menor era $56 \mathrm{mrs}$, el valor monetario de la octava parte del vino no se estimaba sobre los $672 \mathrm{mrs}$ que valía cada arroba de vino, sino sobre los 515,2 mrs por arroba (o bien sobre los 43 mrs por azumbre de la medida menor) que resultaban de descontar del precio de la arroba (o de la azumbre de la medida menor) los impuestos municipales cobrados en moneda y los Tres Millones.

Según indicaba en 1619 el arrendador de la sisa de la Octava Parte, la norma de que no se cobrara dicha sisa de los impuestos municipales ya se seguía a inicios del siglo y se mantuvo durante el resto de la centuria, como se deduce de un Real Decreto de 1668 donde se reconocía que en Madrid seguía sin cobrarse la sisa de la Octava Parte correspondiente a los impuestos municipales ${ }^{24}$.

El método seguido por los arrendadores y contadores municipales para recaudar la sisa del vino de Quiebras y la del Error y la Bajada de Medidas copió el adoptado para la cobranza de la sisa de la Octava Parte del servicio de millones.

Al igual que la sisa de la Octava, la sisa del vino de Quiebras de Millones equivalía a 1,125 azumbres y de nuevo se introdujeron descuentos que reducían su valor, dado que para estimar el monto de esta sisa por arroba los contadores rebajaban de la postura de la azumbre de la medida menor 6 mrs por las sisas del vino de Olivenza y del vino de los Tres Millones. A una postura de $56 \mathrm{mrs}$ por azumbre de la medida menor, el valor monetario devengado por cada arroba de vino en concepto de la sisa de Quiebras de Millones era igual al producto de multiplicar 1,125 por $50 \mathrm{mrs}$, y al resultado, $56,25 \mathrm{mrs}$, se le añadían otros $2 \mathrm{mrs}$, con lo que el valor del vino de Quiebras alcanzaba los 58,25 mrs por arroba (4,85 mrs por azumbre de la medida menor o 3,6 mrs por litro).

Por último, los contadores calculaban el valor de las sisas de la Bajada de Medidas y del Error de Medidas. Cada una de estas dos sisas equivalía a 3,5 cuartillos, pero en este caso no había descuentos de ningún género, de forma que para conocer el valor de las sumas cobradas por arroba de vino para

\footnotetext{
${ }^{24}$ AHN, Consejos, libro 1.253, fols. 126-ss. AVM, Secretaría, 3-276-10.
} 
pagar estas dos sisas basta por multiplicar el precio de postura de la azumbre de la medida menor por 0,875 . Si de nuevo tomamos como referencia la postura de $56 \mathrm{mrs}$, cada una de estas sisas ascendía, por lo tanto, a $49 \mathrm{mrs}$ por arroba (4,08 mrs por azumbre de la medida menor o 3,5 mrs por litro).

Estas normas se respetaron durante la mayor parte siglo XVII, hasta inicios de los años 80, aunque hubo algunos cambios de breve duración. Según hemos indicado, en los años 30 y 40 se introdujeron algunas novedades poco duraderas en la cobranza de los tributos sobre el vino y a esto debe sumarse que desde abril de 1683 los tributos (monetarios y en especie) cobrados por el municipio sobre este producto se redujeron a una cantidad fija.

Con motivo del Medio de la Sal, la capital se vio obligada a realizar un acopio de este producto cuyo coste fue 265.000 ducados y para reunir esta suma el ayuntamiento decidió sustituir la sisa de la Octava Parte del servicio de millones por un gravamen de $5 \mathrm{mrs}$ por azumbre de vino ordinario que se cobró hasta el 31 de julio de 1632, cuando se reintrodujeron los millones ${ }^{25}$.

Poco después, en octubre de 1639 las Cortes decidieron unificar todos los tributos monetarios y en especie cobrados sobre el vino para pagar los servicios de millones en una sisa, elevando el número de azumbres de la medida menor obtenidas de cada arroba de vino en Castilla de 9,125 a 11,5. En el caso de Madrid, el municipio decidió elevar esta cantidad hasta 13 azumbres desde el 1 de noviembre de 1639, de las cuales 3,5 se destinaron a pagar los servicios de millones y 1,5 al pago de las quiebras, en tanto que el valor de los tributos municipales devengados por cada arroba (56 mrs) no se modificó. Esta reforma se mantuvo hasta abril de 1641, cuando cesó la imposición de las 3,5 azumbres y se retornó al sistema tradicional ${ }^{26}$.

$\mathrm{Si}$ las reformas que acabamos de indicar estuvieron ligadas a cambios en la cobranza de los servicios de millones y tuvieron una duración breve, a inicios de los años 80 se introdujo un cambio más duradero, impulsado por el municipio. A causa del elevado número de tributos sobre el vino y de las dificultades provocadas por la existencia de arriendos separados para la cobranza de cada uno de ellos, desde los años 70 se comenzaron a arrendar conjuntamente al Gremio de Taberneros todos los tributos sobre el vino controlados por la villa, quedando fuera del contrato la sisa de la Octava Parte y las cargas aplicadas sobre el vino para la paga de la alcabala y los cientos. Las circunstancias creadas por la deflación de inicios de 1680 crearon una atmósfera propicia para la rebaja de la carga tributaria que recaía sobre el vino a la que nos referiremos en el próximo apartado y en abril de 1683 se decidió rebajar el valor de los tributos del arriendo conjunto de las sisas del vino de 10,6 reales por arroba a 9,5. Nuestras fuentes indican que esta suma se cobraba todavía en 1722, y merece la pena señalar que esta cantidad era fija, sin variar en respuesta a las oscilaciones del precio del vino,

25 AHN, Consejos, libro 1.216, fols. 16 y 311.

26 AHN, Consejos, libro 1.224, fol. 56 y libro 1.226, fol. 84 . 
de suerte que el valor monetario de los impuestos en especie incluidos en el arriendo (la sisa del Vino de Quiebras de Millones y las del Error y Bajada de Medidas) no se modificó tras 1683 y éstos se convirtieron, en realidad, en impuestos monetarios (aunque no se alterara el número de azumbres de la medida menor obtenidas de cada arroba de vino $)^{27}$.

\section{EL ALZA DE LA CARGA FISCAL SOBRE EL VINO}

El Cuadro 4 ofrece el valor medio quinquenal (en términos porcentuales) de los impuestos reales, Sisas Reales y Sisas Municipales cobrados sobre el litro de vino en Madrid entre 1606 y 1700. Este cuadro se ha realizado a partir de las posturas de la azumbre de la medida menor de vino ordinario fijadas por la Sala de Alcaldes de Casa y Corte, que establecían el precio al que los miembros del Gremio de los Taberneros de Villa debían vender su vino, lo cual nos ha permitido calcular los precios del litro de vino ordinario (apéndice). Para estimar el valor de los impuestos monetarios y en especie sobre cada litro de vino hemos seguido las normas de los contadores madrileños expuestas en el apartado anterior.

En 1606-10 los tributos municipales y reales representaban el 27 por cien del precio del litro de vino ordinario, porcentaje que no varió demasiado hasta 1631-35. La reintroducción de los millones en 1632 señaló el comienzo de una fase presidida por la aparición de nuevos tributos sobre el vino que terminó en 1667 con la entrada de la sisa del Error de Medidas. Como resultado, entre 1666 y 1670 los tributos representaron alrededor del 65 por cien del precio del litro de vino ordinario.

La creciente importancia de los tributos sobre el vino en Madrid no escapó a las autoridades, que en varios memoriales de las décadas de los años 60 y 70 mostraron su preocupación por este fenómeno, y las circunstancias creadas por las medidas deflacionistas de febrero de 1680 reforzaron este interés.

La baja del vellón de febrero de 1680 provocó que en abril del mismo año la Sala de Alcaldes rebajara la postura de la azumbre de la medida menor de vino ordinario de 64 a $56 \mathrm{mrs}$, y el precio del litro de esta bebida cayó de 47,7 mrs a 41,7 . Esto provocó un alza en el peso de los tributos sobre el vino ${ }^{28}$. Si con la postura de $64 \mathrm{mrs}$ por azumbre de la medida menor (47,7 mrs por litro) en vigor en 1679 y los primeros meses de 1680 los tributos habían representado el 63 por cien del precio del vino, con la nueva de $56 \mathrm{mrs}$ (41,7 mrs por litro de vino) su peso creció hasta el 67 por cien. Para adaptarse al nuevo marco creado por la deflación, en marzo de 1680 una consulta del Consejo de Castilla aconsejaba aligerar los tributos sobre el vino, evitando un alza de la carga fiscal sobre este producto, y en abril de 1683 el municipio redujo los impuestos

27 AVM, Secretaría, 3-303-21 y 3-250-4.

28 AHN, Alcaldes, libro 1.265, fol. 282; libro 1.282, fol. 507; libro 1.283, fol. 114 y libro 1.285, fols. 53 y 466. AVM, Secretaría, 3-267-4 y 3-492-25. 


\section{CUADRO 4}

VALOR MEDIO QUINQUENAL DE LOS IMPUESTOS REALES (MILLONES, ALCABALAS Y CIENTOS), SISAS REALES Y SISAS MUNICIPALES SOBRE EL VINO EN MADRID, 1606-1700

(En porcentaje del precio de venta al consumo)

\begin{tabular}{|l|c|c|c|c|}
\hline & $\mathbf{( 1 )}$ & $\mathbf{( 2 )}$ & $\mathbf{( 3 )}$ & TOTAL \\
\hline $1606-10$ & 19,5 & & 7,5 & $\mathbf{2 7 , 0}$ \\
\hline $1611-15$ & 17,0 & & 9,6 & $\mathbf{2 6 , 6}$ \\
\hline $1616-20$ & 16,4 & & 13,6 & $\mathbf{3 0 , 0}$ \\
\hline $1621-25$ & 14,1 & & 17,0 & $\mathbf{3 1 , 1}$ \\
\hline $1626-30$ & 14,2 & & 16,3 & $\mathbf{3 0 , 5}$ \\
\hline $1631-35$ & 17,8 & & 18,9 & $\mathbf{3 6 , 7}$ \\
\hline $1636-40$ & 31,2 & & 13,5 & $\mathbf{4 4 , 7}$ \\
\hline $1641-45$ & 40,1 & & 12,3 & $\mathbf{5 2 , 5}$ \\
\hline $1646-50$ & 38,3 & & 14,5 & $\mathbf{5 2 , 8}$ \\
\hline $1651-55$ & 31,4 & 0,5 & 14,2 & $\mathbf{4 6 , 2}$ \\
\hline $1656-60$ & 30,3 & 6,1 & 17,3 & $\mathbf{5 3 , 7}$ \\
\hline $1661-65$ & 28,1 & 9,3 & 21,8 & $\mathbf{5 9 , 3}$ \\
\hline $1666-70$ & 17,2 & 18,2 & 28,3 & $\mathbf{6 3 , 7}$ \\
\hline $1671-75$ & 17,2 & 18,2 & 31,1 & $\mathbf{6 6 , 5}$ \\
\hline $1676-80$ & 15,1 & 19,4 & 30,0 & $\mathbf{6 4 , 5}$ \\
\hline $1681-85$ & 13,3 & 21,1 & 29,2 & $\mathbf{6 3 , 7}$ \\
\hline $1686-90$ & 11,7 & 21,0 & 29,0 & $\mathbf{6 1 , 7}$ \\
\hline $1691-95$ & 11,5 & 19,8 & 27,3 & $\mathbf{5 8 , 7}$ \\
\hline $1696-00$ & 12,1 & 22,1 & 30,4 & $\mathbf{6 4 , 6}$ \\
\hline & & & & \\
\hline
\end{tabular}

(1): impuestos reales. (2): Sisas Reales. (3): Sisas Municipales. Total: (1)+(2)+(3). Fuente: apéndice.

de las 13 sisas del vino que se arrendaban en común de 10,6 reales por arroba a 9,5. Esto representaba una moderada rebaja del 11,5 por cien, explicable por la necesidad de pagar los intereses de la deuda municipal ${ }^{29}$.

El arriendo de las 13 sisas del vino sólo incluía los tributos controlados por la hacienda madrileña. Si a los 9,5 reales antes citados añadimos las sumas cobradas por la sisa de la Octava Parte, controlada por la Corona, y la alcabala y los cientos, cobrados por los gremios de la capital, se concluye

29 AHN, Consejos, legajo 7190. 
que entre 1683 y 1700 el valor de los tributos sobre el litro de vino osciló alrededor de los 24-26 mrs. Estas cantidades ascendían al 58-65 por cien del precio del vino, por lo que, en términos porcentuales, el peso de los impuestos sobre esta bebida entre 1683 y 1700 se mantuvo en niveles similares a los de los años 60 y 70 del siglo, lo que da una buena idea de lo moderado de la rebaja de la carga tributaria de la primavera de 1683 y de la manera en que la deuda municipal contraída por Madrid en las décadas centrales del XVII para efectuar donativos a la Corona limitaba la capacidad del municipio para aligerar los tributos sobre el vino.

Según venimos señalando, la distinción entre los impuestos reales y municipales en el Madrid del siglo XVII resultaba muy borrosa, ya que buena parte de los impuestos municipales pagaban los intereses de los efectistas, por lo que resulta más apropiado considerar a este último tipo de tributos municipales como algo más cercano a los impuestos reales que a aquellos destinados a atender las necesidades ordinarias de la villa. Por este motivo, el Cuadro 5 presenta la repercusión sobre los precios del vino de los impuestos municipales aplicados para las necesidades que podemos considerar estrictamente municipales, los impuestos municipales introducidos para el pago de los efectos de villa, las Sisas Reales y los impuestos reales (millones, alcabalas y cientos).

El Cuadro 5 atestigua la creciente importancia de los impuestos municipales creados para pagar los intereses de los efectos y demuestra que sus repercusiones sobre los precios del litro de vino fueron muy superiores desde 1666 a las de los impuestos municipales propiamente dichos, que durante la mayor parte del siglo representaron alrededor del 10 por cien de los precios de esta bebida. Los impuestos municipales aplicados para las necesidades extra municipales, las Sisas Reales y los impuestos reales financiaron las necesidades de la Real Hacienda, y si consideramos de forma conjunta a estas tres clases de tributos se observa que desde 1636-40 su peso rebasó con holgura al de los impuestos municipales y que tras 1665 representaron el 50-55 por cien de los precios del litro de vino, lo que constituye una significativa prueba del modo en que las necesidades de la Corona causaron el ascenso de la carga fiscal sobre esta bebida.

Aunque el incremento de la carga tributaria sobre el vino en el Madrid del Seiscientos es una muestra de la tendencia al avance de la tributación indirecta en Castilla y Europa, la preferencia por el vino como fuente de ingresos fiscales en Madrid y Castilla constituye un aspecto de relieve si recordamos que en otras zonas como Holanda, en donde también se desarrolló este tipo de tributación durante el mismo período, los tributos indirectos se recaudaron sobre una amplia gama de artículos, como los cereales, harinas, cerveza, turba, lo que evitó que la carga fiscal se concentrara sobre un solo producto ${ }^{30}$.

30 't Hart, (1999, pp. 317-21). Algo similar podría decirse de la fiscalidad inglesa tras 1688. O’Brien y Hunt, (1999, pp. 60-ss). 


\section{CUADRO 5}

VALOR MEDIO QUINQUENAL DE LOS IMPUESTOS MUNICIPALES, IMPUESTOS MUNICIPALES CREADOS PARA NECESIDADES EXTRA-MUNICIPALES, SISAS REALES E IMPUESTOS REALES SOBRE EL VINO ORDINARIO EN MADRID (En porcentaje del precio de venta al consumo).

\begin{tabular}{|l|c|c|c|c|c|c|}
\hline & $\mathbf{( 1 )}$ & $\mathbf{( 2 )}$ & $\mathbf{( 3 )}$ & $\mathbf{( 4 )}$ & Tot. 1 & Tot. 2 \\
\hline $1606-10$ & 7,5 & & & 19,5 & 19,5 & $\mathbf{2 7 , 0}$ \\
\hline $1611-15$ & 9,6 & & & 17,0 & 17,0 & $\mathbf{2 6 , 6}$ \\
\hline $1616-20$ & 13,6 & & & 16,4 & 16,4 & $\mathbf{3 0 , 0}$ \\
\hline $1621-25$ & 17,0 & & & 14,1 & 14,1 & $\mathbf{3 1 , 1}$ \\
\hline $1626-30$ & 16,3 & & & 14,2 & 14,2 & $\mathbf{3 0 , 5}$ \\
\hline $1631-35$ & 18,9 & & & 17,8 & 17,8 & $\mathbf{3 6 , 7}$ \\
\hline $1636-40$ & 13,5 & & & 31,2 & 31,2 & $\mathbf{4 4 , 7}$ \\
\hline $1641-45$ & 11,3 & 1,0 & & 40,1 & 41,1 & $\mathbf{5 2 , 5}$ \\
\hline $1646-50$ & 11,2 & 3,3 & & 38,3 & 41,6 & $\mathbf{5 2 , 8}$ \\
\hline $1651-55$ & 11,5 & 2,7 & 0,5 & 31,4 & 34,6 & $\mathbf{4 6 , 2}$ \\
\hline $1656-60$ & 12,3 & 5,0 & 6,1 & 30,3 & 41,4 & $\mathbf{5 3 , 7}$ \\
\hline $1661-65$ & 12,0 & 9,8 & 9,3 & 28,1 & 47,2 & $\mathbf{5 9 , 3}$ \\
\hline $1666-70$ & 11,0 & 17,2 & 18,2 & 17,2 & 52,6 & $\mathbf{6 3 , 7}$ \\
\hline $1671-75$ & 11,0 & 20,1 & 18,2 & 17,2 & 55,5 & $\mathbf{6 6 , 5}$ \\
\hline $1676-80$ & 10,2 & 19,8 & 19,4 & 15,1 & 54,3 & $\mathbf{6 4 , 5}$ \\
\hline $1681-85$ & 10,3 & 19,1 & 21,1 & 13,3 & 53,5 & $\mathbf{6 3 , 7}$ \\
\hline $1686-90$ & 10,2 & 18,7 & 21,0 & 11,7 & 51,4 & $\mathbf{6 1 , 7}$ \\
\hline $1691-95$ & 9,6 & 17,6 & 19,8 & 11,5 & 48,9 & $\mathbf{5 8 , 7}$ \\
\hline $1696-00$ & 10,7 & 19,7 & 22,1 & 12,1 & 53,9 & $\mathbf{6 4 , 6}$ \\
\hline & & & & & & \\
\hline & & & & & & \\
\hline
\end{tabular}

(1): impuestos municipales sobre el litro de vino. (2): impuestos municipales creados para pagar a los efectistas. (3): Sisas Reales. (4): impuestos reales sobre el litro de vino. Tot 1: valor de todos los impuestos reales y municipales sobre el litro de vino creados para financiar las necesidades reales, directa o indirectamente. $(2)+(3)+(4)$. Total 2 : valor de todos los impuestos reales y municipales sobre el litro de vino. $(1)+(2)+(3)+(4)$. Fuente: apéndice.

La predilección de las autoridades madrileñas y castellanas por los tributos sobre el vino puede explicarse atendiendo a varios factores. Existía un activo comercio de esta bebida en todo el reino y la cobranza de los tributos sobre la misma no parecía difícil, bastando para ello con percibir los impuestos en las puertas de la capital a la entrada del vino, aunque esto no impidió que a lo largo del siglo las entradas ilegales de esta bebida crecieran 
hasta hacerse masivas. Además, el vino tenía una demanda inelástica, lo que animó a las autoridades a recurrir a los tributos sobre esta bebida ${ }^{31}$. A esto debe añadirse que en el Madrid del siglo XVII no todos los productos estuvieron gravados en la misma medida que el vino y que en contrapartida a la gran carga fiscal que recayó sobre esta bebida, la que gravó a la mayor parte de los productos fue menor. Según nuestras estimaciones, en las últimas décadas del siglo los impuestos representaban entre el 30-33 por cien de los precios de la libra de carnero, tocino y aceite en la capital, porcentaje inferior al del vino, aunque nada desdeñable. Sin embargo, el peso de los impuestos sobre el resto de los artículos incluidos en una cesta de la compra de un consumidor madrileño a fines de siglo oscilaba alrededor del 7 por cien, siendo de particular interés que el producto más importante, el pan, estaba prácticamente exento del pago de tributos ${ }^{32}$. La existencia de un conjunto de mantenimientos que soportaban una elevada carga fiscal como las carnes y el vino ayuda a explicar el fracaso de los numerosos proyectos de gravar el trigo, la harina y el pan debatidos a lo largo de los siglos XVI y XVII. En unos momentos en que los tributos encarecían los precios de algunos productos de consumo masivo, debió de parecer aconsejable a las autoridades evitar la creación de nuevos gravámenes sobre el artículo más importante en la dieta de los castellanos, el pan, evitando que un alza de la carga fiscal sobre este mantenimiento provocara bruscas subidas en su precio que hubieran perjudicado la estabilidad de las ciudades del reino ${ }^{33}$.

Medido en maravedís corrientes, el precio del vino experimentó una gran subida a lo largo del siglo XVII. Si situamos una base 100 en 1606, el precio de esta bebida alcanzó un índice 306 en 1666-70, nivel alrededor del cual se mantuvo durante el resto del siglo. Sin embargo, la historia económica y social de Madrid y Castilla de las décadas centrales del Seiscientos estuvo presidida por la elevada inflación causada por las alteraciones de la moneda de vellón y por ello hemos deflactado los precios nominales del litro de vino por el índice de precios en Madrid entre 1596 y 1700 recientemente presentado por Andrés y Lanza ${ }^{34}$. Los resultados de esta operación se muestran en el Gráfico 1, que ofrece la trayectoria de los precios del vino en maravedís constantes en Madrid en el siglo XVII, calculada a través de números índice de una media móvil de siete años.

El Gráfico 1 muestra que, en términos reales, los precios del vino crecieron de forma notable en Madrid a lo largo del siglo XVII. Dentro de esta trayectoria alcista pueden establecerse varias fases. La primera se desarrolló tras la llegada de la Corte en 1606, que impulsó el alza de los precios del vino, aunque a inicios de la década de los 20 se produjo una caída. En 1632 se

\footnotetext{
31 Andrés, (1999).

32 Andrés y Lanza, (2009).

33 Sobre estos proyectos, Fortea, (1990).

34 Andrés y Lanza (2009).
} 


\section{GRÁFICO 1}

PRECIOS DEL LITRO DE VINO EN MADRID EN MARAVEDÍS CONSTANTES, 1606-1700. Base $100=1616-20$

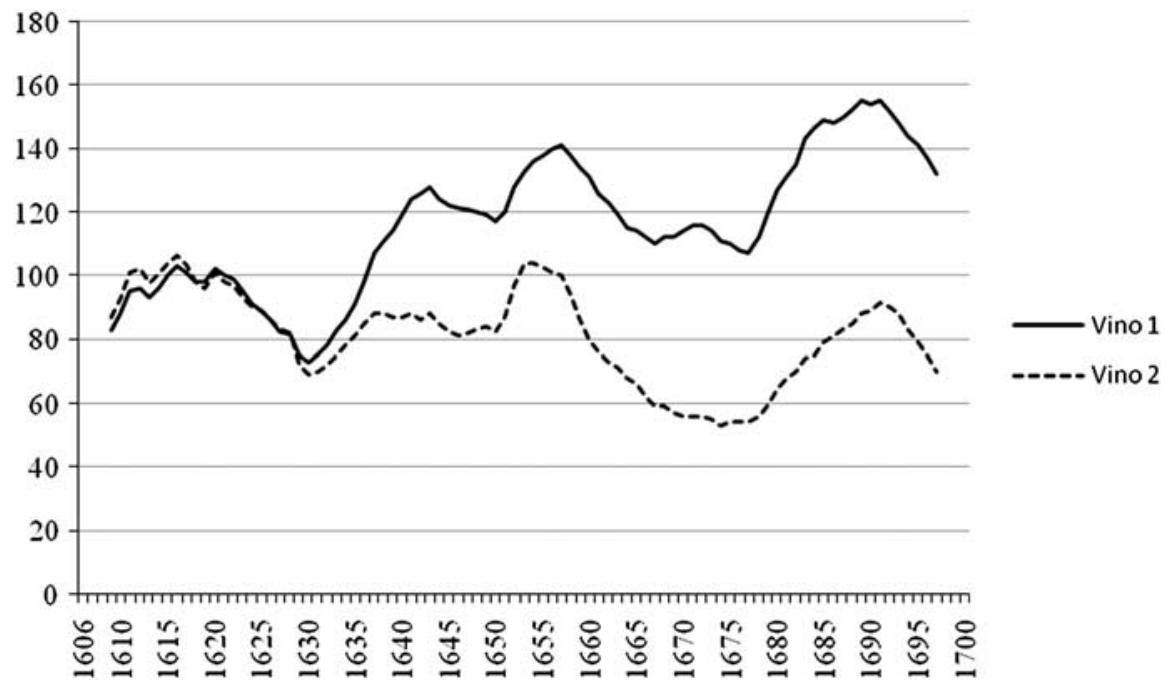

Vino 1: precios del litro de vino incluyendo impuestos. Vino 2: precios del litro de vino excluyendo los impuestos. Fuentes: apéndice.

inició una nueva fase alcista, prolongada hasta 1656-60. A lo largo de la misma los precios del vino en términos constantes crecieron un 86 por cien respecto de 1626-30. Los años centrales del siglo estuvieron presididos por las crecientes exigencias tributarias de la Corona, que se tradujeron en el desarrollo de los servicios de millones tras 1632 con la introducción del servicio de los 24 millones (en 1632), los servicios de los 8.000 soldados y Quiebras de Millones (en 1638 y 1639 respectivamente) y el servicio de los Tres Millones (en 1657), a la que debe añadirse la creación de los tres primeros cientos (en 1639, 1642 y 1657). Además, en este período también aparecieron nuevos impuestos municipales, como la sisa del Vino de la Salud (en 1637), la del Vino de Lérida (en 1644) y la del Vino de Olivenza (en 1657). Todas estas figuras gravaban de forma preferente el vino y provocaron un alza en la carga fiscal que tuvo una responsabilidad esencial en la subida de los precios de esta bebida a lo largo del período. Si, medido en términos constantes, los precios del vino aumentaron cerca de un 86 por cien entre 1626-30 y 1656-60, cuando descontamos los impuestos esta alza se rebaja hasta un más moderado 24 por cien. Entre 1661 y 1680 los precios del vino en términos constantes experimentaron un descenso, aunque se mantuvieron en niveles todavía muy superiores a los de inicios de siglo. Este descenso refleja el hecho de que en esas dos décadas el índice de precios de 
Madrid alcanzó sus niveles más elevados a causa de la inflación del vellón. Para terminar, entre 1680 y 1700 se desarrolló la última fase. En 1686-90 los precios del vino en maravedís constantes alcanzaron los niveles más elevados del siglo, tras una subida de casi el 50 por cien respecto de 1676-80, algo que puede resultar sorprendente cuando se recuerda que las medidas deflacionistas de comienzos de los 80 habían impulsado una brusca caída en los niveles de precios en Castilla y que el último impuesto sobre el vino se había introducido en Madrid en 1667 (la Sisa del Error de Medidas).

Los altos precios del vino en maravedís constantes de las últimas décadas del siglo se explican por el peso de la deuda municipal, que tanto creció entre 1653 y 1679 a causa de la concesión de donativos a la Corona. Según nuestros cálculos, las medidas deflacionistas de inicios de los 80 redujeron el índice de precios en Madrid un 29 por cien en 1680-84 respecto de $1675-79^{35}$. Sin embargo, los precios del vino sólo descendieron el 6 por cien en el mismo período, dado que este producto aportaba una parte sustancial de los ingresos fiscales con los que la villa debía pagar los intereses de la deuda municipal y una caída mayor de sus precios hubiera reducido las recaudaciones de los impuestos sobre esta bebida por debajo del nivel preciso para atender tal objetivo.

Lo anterior indica que el alza de la carga fiscal tuvo una importancia capital en la evolución de los precios del vino a lo largo del siglo y esta conclusión se refuerza cuando analizamos la trayectoria de los precios del vino en maravedís constantes excluyendo los impuestos. Según muestra el Gráfico 1, si descontamos los tributos que gravaban su consumo los precios de esta bebida no sólo no aumentaron, sino que tendieron a caer a lo largo del siglo, siendo destacable que el alza del período 1631-1660 se rebaja de forma notable y que después de 1655 los precios se situaron en niveles incluso inferiores a los de las primeras décadas del siglo.

\section{CONCLUSIONES}

Las páginas anteriores muestran la importancia del vino como fuente de ingresos fiscales para la Hacienda Real y para la Hacienda madrileña en el siglo XVII. Como en el resto de Castilla y en otros estados europeos del período, tanto la Hacienda Real como la hacienda municipal madrileña recurrieron a la tributación indirecta para atender sus necesidades. La gran importancia del vino como fuente de ingresos fiscales constituye una de las principales particularidades del caso madrileño y castellano en el contexto europeo y este protagonismo es más fácil de comprender cuando se recuerda que en contrapartida a la elevada carga fiscal que recayó sobre esta bebida, la que afectó al resto de los productos y mercancías en la capital fue mucho más reducida (con la excepción de la carne y el aceite) y que el alimento más

\footnotetext{
35 Andrés y Lanza, (2009).
} 
importante en la dieta de los castellanos del XVII, el pan, estaba prácticamente exento del pago de impuestos. A finales del siglo, los tributos de todo tipo sobre el vino aportaban el 40-45 por cien del valor global de las recaudaciones de los impuestos municipales y reales recaudados en Madrid (apartado 1) y en el mismo período los diversos gravámenes (monetarios y en especie) sobre esta bebida representaban entre el 60-65 por cien de su precio (apartado 3). Además, el alza de la carga fiscal fue una de las principales causas de la notable subida de los precios del vino en maravedís constantes a lo largo del siglo.

Nuestro trabajo muestra que el crecimiento de la carga fiscal sobre el vino estuvo impulsado por las necesidades de la Corona. A finales del siglo, el 85 por cien del valor anual de las pagas de todos los tributos sobre el vino en la capital procedía de tributos creados para financiar, directa o indirectamente, las necesidades de la Real Hacienda (apartado 1), que representaban más 50 por cien del precio del litro de vino ordinario.

El caso del vino expuesto en estas líneas sugiere que la teoría tradicional acerca de la relación entre la tributación indirecta y los niveles de precios y salarios en la Castilla del siglo XVII estaba en lo cierto y que el avance de la tributación indirecta tuvo importantes efectos sobre ambas variables. Sin embargo, no todos los productos incluidos en la cesta de la compra de un consumidor madrileño en el siglo XVII estaban gravados en la misma medida que el vino, por lo que el efecto de la fiscalidad indirecta sobre los precios y salarios en Madrid fue menor de lo que pudiera pensarse si nos centrásemos exclusivamente en esta bebida. Según nuestras estimaciones, la influencia de los impuestos indirectos sobre los niveles de precios y salarios reales en Madrid sólo comenzó a ser apreciable en el último tercio del siglo, cuando elevaron los niveles de precios en alrededor de un 15-20 por cien, reduciendo los salarios reales en idéntica medida, porcentajes que, aunque inferiores a lo que opinaban los tratadistas de la época, distaban en cualquier caso de ser despreciables ${ }^{36}$.

Por último, la creciente carga fiscal sobre el vino hace que nos preguntemos acerca del modo en que la proliferación de tributos sobre esta bebida en el Madrid del XVII afectó a la producción de vino en las zonas donde se abastecían los taberneros de la capital. Aunque no existe una monografía, en lo que sabemos, sobre la producción de vino en Castilla en el Seiscientos varios trabajos sugieren un panorama donde junto a algún caso de crecimiento se encuentran otros de retroceso de esta actividad. En este siglo se produjo la consolidación del viñedo riojano, a causa de la apertura de nuevos mercados en la cornisa cantábrica y en el norte de Castilla la Vieja. Sin embargo, en el mismo período retrocedieron los viñedos del valle del Duero, Toro, Medina del Campo, y este cultivo también retrocedió en la Andalucía Occidental y el arzobispado de Toledo ${ }^{37}$. La crisis del viñedo en esta última

36 Andrés y Lanza, (2009).

37 Ibáñez Rodríguez, (2002, pp. 41-53). Sebastián Amarilla; García Montero; Zafra Oteyza y Bernardos, (2008, pp. 18-ss). Llopis y González- Mariscal, (2010, pp. 23-ss). 
zona, dentro de la que se incluía Madrid, resulta de particular interés porque varios testimonios de la época sugieren que, a diferencia de lo sucedido en el resto del arzobispado, el viñedo avanzó en los alrededores de la capital a lo largo del siglo y un estudio sobre las relaciones entre la fiscalidad y el cultivo de la vid en los alrededores de Madrid ayudaría a resolver este problema, elevando nuestros conocimientos acerca de la manera en que el alza de la carga fiscal sobre el vino en la Castilla del XVII afectó al cultivo de la vid ${ }^{38}$.

\section{FUENTES}

Archivo Histórico Nacional, (AHN), Madrid.

Archivo de la Villa de Madrid, (AVM), Madrid.

Biblioteca Nacional, (BN), Madrid.

\section{BIBLIOGRAFÍA}

ANDRÉs, J. I. (1999): La fiscalidad en Castilla en el siglo XVII. Los servicios de millones. Lejona: Universidad.

ANDRÉs, J. I. (2006): «Fiscalidad real y fiscalidad municipal en Castilla durante el siglo XVII: el caso de Madrid». Investigaciones de Historia Económica 5, pp. 41-70.

ANDRÉs, J. I. (2007): «Government Policies and the Development of the Financial Markets: The Case of Madrid in the Seventeenth Century», en F. Piola Caselli (ed.), Government Debts and Financial Markets in Europe. Londres: Pickering and Chatto, pp. 67-80.

ANDRÉs, J. I. y LANZA, R. (2008): «Estructura y evolución de los ingresos de la Real Hacienda de Castilla en el siglo XVII». Studia Storica 30, pp. 147-190.

AndrÉs, J. I. y Lanza, R. (2009): "Urban Taxation, Prices, Wages and Economic Growth in 17th Century Castile: the Case of Madrid», comunicación presentada al XV World Economic History Congress, Utrecht, 2009.

Bonney, R. (ed.) (1999): The Rise of the Fiscal State in Europe, c.1200-1815. Oxford: Oxford University Press, pp. 53-100.

De La Hoz, C. (1988): «El sistema fiscal de Madrid en el Antiguo Régimen: las sisas». Anales del Instituto de Estudios Madrileños XXV, pp. 371-386.

ForteA, J. I. (1981): Córdoba en el siglo XVI: las bases demográficas y económicas de un expansión urbana. Córdoba: Monte de Piedad.

Fortea, J. I. (1990): Monarquía y Cortes en Castilla. Las ciudades ante la política fiscal del Felipe II. Valladolid: Ámbito.

38 Sobre los avances del viñedo en los alrededores de Madrid, AVM, Secretaría, 3-256-7 y AHN, Estado, libro 871, fols. 217-25 y Consejos, legs. 26.260, 26.261 y 26.262 . 
García García, C. (1996): La crisis de las Haciendas locales. De la reforma administrativa a la reforma fiscal, (1743-1845). Valladolid: Junta de Castilla y León.

García SANZ, A. (1991): «Repercusiones de la fiscalidad sobre la economía castellana en los siglos XVI y XVII». Hacienda Pública Española I, pp. 15-24.

Gutiérrez Alonso, A. (1989): Estudio sobre la decadencia de Castilla. La ciudad de Valladolid en el siglo XVII. Valladolid: Universidad.

Hamilton, E. (1975): El tesoro americano y la revolución de los precios. Barcelona: Crítica.

't Hart, M. (1999): «The United Provinces, 1579-1806», en R. Bonney (ed.), The Rise of the Fiscal State in Europe, c.1200-1815. Oxford: Oxford University Press, pp. 309-326.

Huetz De Lemps, A. (1967): Vignobles et vins du Nord-Ouest de l'Espagne. Burdeos, vol I.

IbÁÑEz RodRíguez, S. (2002): «La consolidación del vino de Rioja en el siglo XVII». Historia Agraria 26, pp. 35-68.

LloPIS, E. y GonZÁLEZ-MARISCAL, M. (2010): «Un crecimiento tempranamente quebrado: el producto agrario en Andalucía Occidental durante la Edad Moderna». Historia Agraria 50, pp. 13-42.

Marcos Martín, A. (2006): «¿ंFue la fiscalidad regia un factor de la crisis?», en G. Parker (ed.), La crisis de la Monarquía de Felipe IV. Barcelona: Crítica, pp. 173-253.

O’Brien, P. y Hunt, P. (1999): «England, 1485-1815», en R. Bonney (ed.), The Rise of the Fiscal State in Europe, c.1200-1815. Oxford: Oxford University Press, pp. 53-100.

Ruiz MARTín, F. (1978): «Procedimientos crediticios para la recaudación de los tributos fiscales en las ciudades castellanas en los siglos XVI y XVII: el caso de Valladolid», Dinero y Crédito (siglos XVI al XX). Madrid: Moneda y Crédito, pp. 37-47.

Sebastí́n Amarilla, J. A., García Montero, H., Zafra Oteyza, J. y Bernardos SANZ, J. U. (2008): «Del crecimiento a la decepción. La producción agraria en Castilla la Mancha en la Edad Moderna. Una primera aproximación». Comunicación presentada a la sesión El PIB y las macromagnitudes económicas en la España del Antiguo Régimen, IX Congreso de la Asociación Española de Historia Económica, Murcia.

Stensgaard, N. (1978): "The Seventeenth-Century Crisis», en G. Parker y L. Smith (eds), The General Crisis of the Seventeenth Century. Londres: Routledge, pp. 26-56.

Yun, B. (1990): «Estudio introductorio», en J. Ruiz de Celada, (1777), Estado de la Bolsa de Valladolid. Examen de sus tributos, cargas y medios de su extinción, de su gobierno y de su reforma. Valladolid: Universidad, pp. 7-41. 
CUADRO 1

VALOR DE LOS IMPUESTOS REALES, SISAS REALES Y SISAS MUNICIPALES POR LITRO DE VINO ORDINARIO,

MADRID 1606-1700

(Datos en mrs corrientes por litro)

\begin{tabular}{|c|c|c|c|c|c|c|c|}
\hline & (1) & (2) & (3) & (4) & TOTAL & (5) & (6) \\
\hline 1606 & 1,1 & 1,5 & & 1,0 & 3,6 & 13,6 & 24,0 \\
\hline 1607 & 1,1 & 1,4 & & 1,0 & 3,5 & 12,5 & 22,0 \\
\hline 1608 & 1,1 & 1,7 & & 1,0 & 3,8 & 14,7 & 26,0 \\
\hline 1609 & 1,1 & 1,5 & & 1,0 & 3,6 & 13,4 & 23,6 \\
\hline 1610 & 1,1 & 1,4 & & 1,0 & 3,5 & 12,5 & 22,1 \\
\hline 1611 & 1,1 & 1,8 & & 1,0 & 4,0 & 15,7 & 27,7 \\
\hline 1612 & 1,1 & 1,9 & & 2,0 & 5,0 & 17,3 & 30,6 \\
\hline 1613 & 1,1 & 2,1 & & 2,0 & 5,2 & 19,3 & 34,0 \\
\hline 1614 & 1,1 & 2,8 & & 2,0 & 5,9 & 24,4 & 43,0 \\
\hline 1615 & 1,1 & 1,9 & & 2,0 & 5,0 & 17,7 & 31,3 \\
\hline 1616 & 1,1 & 1,1 & & 2,0 & 4,2 & 11,5 & 20,3 \\
\hline 1617 & 1,1 & 2,0 & & 2,0 & 5,1 & 18,3 & 32,3 \\
\hline 1618 & 1,1 & 2,5 & & 2,1 & 5,7 & 22,7 & 40,0 \\
\hline 1619 & 1,1 & 2,0 & & 3,0 & 6,1 & 19,3 & 34,0 \\
\hline 1620 & 1,1 & 1,6 & & 3,0 & 5,7 & 16,3 & 28,8 \\
\hline 1621 & 1,1 & 1,7 & & 3,0 & 5,8 & 16,7 & 29,5 \\
\hline 1622 & 0,85 & 1,5 & & 3,0 & 5,3 & 15,5 & 27,3 \\
\hline
\end{tabular}




\begin{tabular}{|c|c|c|c|c|c|c|}
\hline \multicolumn{7}{|c|}{ CUADRO 1 (Cont.) } \\
\hline 1623 & 0,85 & 1,7 & 3,0 & 5,6 & 17,0 & 30,0 \\
\hline 1624 & 0,5 & 1,6 & 3,0 & 5,1 & 15,9 & 28,0 \\
\hline 1625 & 0,5 & 2,5 & 3,0 & 6,0 & 23,6 & 41,6 \\
\hline 1626 & 0,7 & 2,1 & 3,0 & 5,8 & 20,2 & 35,6 \\
\hline 1627 & 0,7 & 1,8 & 3,0 & 5,5 & 17,8 & 31,3 \\
\hline 1628 & 0,7 & 2,2 & 3,0 & 5,9 & 20,5 & 36,1 \\
\hline 1629 & 0,7 & 1,4 & 3,0 & 5,1 & 14,7 & 26,0 \\
\hline 1630 & 0,7 & 1,9 & 3,2 & 5,8 & 18,3 & 32,3 \\
\hline 1631 & 0,7 & 1,9 & 3,5 & 6,1 & 17,9 & 32,0 \\
\hline 1632 & 0,7 & 2,4 & 3,5 & 6,6 & 15,3 & 28,6 \\
\hline 1633 & 0,7 & 2,5 & 3,5 & 6,7 & 17,9 & 31,5 \\
\hline 1634 & 0,85 & 2,8 & 3,5 & 7,1 & 19,0 & 33,5 \\
\hline 1635 & 0,85 & 3,4 & 3,5 & 7,7 & 22,4 & 39,5 \\
\hline 1636 & 0,85 & 3,7 & 3,5 & 8,0 & 21,0 & 37,0 \\
\hline 1637 & 0,85 & 4,1 & 4,0 & 9,0 & 23,5 & 41,5 \\
\hline 1638 & 0,85 & 7,0 & 3,6 & 11,4 & 27,8 & 49,0 \\
\hline 1639 & 1,0 & 9,6 & 3,5 & 14,1 & 27,9 & 43,1 \\
\hline 1640 & 1,2 & 12,8 & 3,5 & 17,5 & 32,8 & 40,6 \\
\hline 1641 & 1,0 & 10,3 & 3,5 & 14,8 & 27,9 & 41,6 \\
\hline 1642 & 0,9 & 10,6 & 3,4 & 14,9 & 31,0 & 49,0 \\
\hline 1643 & 2,2 & 10,2 & 3,5 & 15,9 & 28,6 & 45,2 \\
\hline
\end{tabular}


CUADRO 1 (Cont.)

\begin{tabular}{|c|c|c|c|c|c|c|c|}
\hline & (1) & (2) & (3) & (4) & TOTAL & (5) & (6) \\
\hline 1644 & 2,3 & 10,4 & & 4,0 & 16,7 & 31,3 & 47,3 \\
\hline 1645 & 2,0 & 10,0 & & 4,4 & 16,4 & 30,7 & 44,6 \\
\hline 1646 & 2,0 & 10,9 & & 4,4 & 17,3 & 35,2 & 51,1 \\
\hline 1647 & 1,85 & 9,4 & & 4,4 & 15,6 & 27,8 & 40,3 \\
\hline 1648 & 1,6 & 8,9 & & 4,4 & 14,9 & 25,0 & 36,5 \\
\hline 1649 & 1,5 & 10,0 & & 4,4 & 15,9 & 31,0 & 45,0 \\
\hline 1650 & 1,5 & 10,4 & & 4,4 & 16,3 & 32,4 & 47,0 \\
\hline 1651 & 1,5 & 11,0 & & 4,4 & 16,9 & 35,8 & 52,0 \\
\hline 1652 & 1,5 & 9,7 & & 5,6 & 16,8 & 35,1 & 51,0 \\
\hline 1653 & 1,5 & 9,3 & & 5,6 & 16,4 & 33,5 & 48,6 \\
\hline 1654 & 1,5 & 10,0 & 0,27 & 5,6 & 17,3 & 37,9 & 54,0 \\
\hline 1655 & 1,5 & 11,2 & 0,27 & 5,6 & 18,5 & 44,1 & 64,0 \\
\hline 1656 & 1,9 & 11,2 & 0,27 & 5,6 & 19,0 & 44,1 & 64,0 \\
\hline 1657 & 1,9 & 8,5 & 2,1 & 6,4 & 18,9 & 33,6 & 48,8 \\
\hline 1658 & 1,9 & 8,7 & 3,0 & 6,9 & 20,5 & 35,8 & 52,0 \\
\hline 1659 & 2,5 & 8,7 & 3,0 & 6,9 & 21,1 & 36,2 & 52,5 \\
\hline 1660 & 2,5 & 9,2 & 3,0 & 6,9 & 21,6 & 38,6 & 56,0 \\
\hline 1661 & 1,6 & 8,1 & 3,0 & 6,9 & 19,6 & 33,0 & 48,0 \\
\hline 1662 & 2,6 & 8,7 & 3,0 & 6,9 & 21,2 & 35,8 & 52,0 \\
\hline 1663 & 2,6 & 9,3 & 3,0 & 8,5 & 23,4 & 40,2 & 56,0 \\
\hline
\end{tabular}




\begin{tabular}{|c|c|c|c|c|c|c|c|}
\hline \multicolumn{8}{|c|}{ CUADRO 1 (Cont.) } \\
\hline 1664 & 2,6 & 9,3 & 3,0 & 10,0 & 24,9 & 41,7 & 56,0 \\
\hline 1665 & 2,6 & 6,4 & 6,0 & 10,0 & 25,0 & 41,7 & 56,0 \\
\hline 1666 & 2,5 & 4,7 & 7,6 & 10,0 & 24,8 & 41,7 & 56,0 \\
\hline 1667 & 2,5 & 4,7 & 7,6 & 10,0 & 24,8 & 41,7 & 56,0 \\
\hline 1668 & 2,5 & 4,7 & 7,6 & 13,0 & 27,8 & 41,7 & 56,0 \\
\hline 1669 & 2,5 & 4,7 & 7,6 & 13,0 & 27,8 & 41,7 & 56,0 \\
\hline 1670 & 2,5 & 4,7 & 7,6 & 13,0 & 27,8 & 41,7 & 56,0 \\
\hline 1671 & 2,5 & 4,7 & 7,7 & 13,2 & 28,1 & 42,5 & 57,0 \\
\hline 1672 & 2,5 & 4,7 & 7,6 & 13,0 & 27,8 & 41,7 & 56,0 \\
\hline 1673 & 2,5 & 4,7 & 7,6 & 13,0 & 27,8 & 41,7 & 56,0 \\
\hline 1674 & 2,5 & 4,7 & 7,6 & 13,0 & 27,8 & 41,7 & 56,0 \\
\hline 1675 & 2,5 & 4,7 & 7,6 & 13,0 & 27,8 & 41,7 & 56,0 \\
\hline 1676 & 2,5 & 4,4 & 7,4 & 12,6 & 26,9 & 38,8 & 52,0 \\
\hline 1677 & 2,5 & 4,7 & 7,6 & 13,0 & 27,8 & 41,7 & 56,0 \\
\hline 1678 & 2,5 & 5,6 & 9,1 & 14,8 & 32,0 & 53,7 & 72,0 \\
\hline 1679 & 2,5 & 3,6 & 10,0 & 13,9 & 30,0 & 47,7 & 64,0 \\
\hline 1680 & 2,6 & 3,2 & 9,6 & 13,3 & 28,7 & 43,5 & 58,0 \\
\hline 1681 & 2,7 & 3,0 & 9,4 & 13,0 & 28,0 & 41,7 & 56,0 \\
\hline 1682 & 2,7 & 3,0 & 9,4 & 13,0 & 28,0 & 41,7 & 56,0 \\
\hline 1683 & 2,5 & 3,0 & 8,6 & 11,9 & 26,1 & 41,7 & 56,0 \\
\hline 1684 & 2,5 & 3,0 & 8,4 & 11,6 & 25,5 & 41,7 & 56,0 \\
\hline
\end{tabular}


CUADRO 1 (Cont.)

\begin{tabular}{|c|c|c|c|c|c|c|c|}
\hline & (1) & (2) & (3) & (4) & TOTAL & (5) & (6) \\
\hline 1685 & 2,5 & 3,0 & 8,4 & 11,6 & 25,5 & 41,7 & 56,0 \\
\hline 1686 & 1,9 & 2,7 & 8,4 & 11,6 & 24,6 & 38,6 & 51,8 \\
\hline 1687 & 1,9 & 2,5 & 8,4 & 11,6 & 24,4 & 36,5 & 49,0 \\
\hline 1688 & 1,9 & 3,0 & 8,4 & 11,6 & 24,9 & 41,7 & 56,0 \\
\hline 1689 & 1,9 & 3,0 & 8,4 & 11,6 & 24,9 & 41,7 & 56,0 \\
\hline 1690 & 1,9 & 3,0 & 8,4 & 11,6 & 24,9 & 41,7 & 56,0 \\
\hline 1691 & 1,9 & 3,0 & 8,4 & 11,6 & 24,9 & 41,7 & 56,0 \\
\hline 1692 & 1,9 & 3,3 & 8,4 & 11,6 & 25,2 & 44,7 & 60,0 \\
\hline 1693 & 1,9 & 3,1 & 8,4 & 11,6 & 25,0 & 42,5 & 57,0 \\
\hline 1694 & 1,9 & 3,0 & 8,4 & 11,6 & 24,9 & 41,7 & 56,0 \\
\hline 1695 & 1,9 & 3,0 & 8,4 & 11,6 & 24,9 & 41,7 & 56,0 \\
\hline 1696 & 1,9 & 3,0 & 8,4 & 11,6 & 24,9 & 41,7 & 56,0 \\
\hline 1697 & 1,9 & 2,5 & 8,4 & 11,6 & 24,4 & 35,8 & 48,0 \\
\hline 1698 & 1,9 & 2,5 & 8,4 & 11,6 & 24,4 & 35,8 & 48,0 \\
\hline 1699 & 1,9 & 3,0 & 8,4 & 11,6 & 24,9 & 41,2 & 55,3 \\
\hline 1700 & 1,9 & 2,5 & 8,4 & 11,6 & 24,4 & 35,8 & 48,0 \\
\hline
\end{tabular}

(1): valor de la alcabala y cientos cobrados por litro de vino. (2): valor de los servicios de millones por litro de vino ordinario. (3): valor de las Sisas Reales por litro de vino ordinario. (4): valor de las Sisas Municipales por litro de vino ordinario. TOTAL: (1)+(2)+(3)+(4). (5): precio del litro de vino ordinario. (6): postura de la azumbre de la medida menor de vino ordinario. Fuente: para el valor de los impuestos sobre el litro de vino, AVM, Secretaría 2-243-7 y 3-276-10 y AHN, Consejos, libros $1.200,1.201,1.202,1.215,1.216,1.218,1.219,1.220,1.221,1.222,1.223,1.224,1.226,1.228,1.230,1.232,1.238,1.239,1.243,1.247$, 1.246 y 1.247. Para los precios del vino, AHN, Consejos, libros 1.200 al 1.285 